\title{
Subjective contours in stereoscopic space
}

\author{
C. L. G. WHITMORE, R. B. LAWSON, and C. E. KOZORA \\ University of Vermont, Burlington, Vermont 05401
}

\begin{abstract}
Stereoscopic depth and subjective contour clarity were manipulated by varying the type of monocular configuration as well as magnitude and direction of disparity. The clarity of the subjective contours was influenced significantly by both magnitude and direction of disparity and by the type of monocular configuration. Subjective contours were always less clear when the objective monocular contour was discontinuous regardless of disparity. Stereoscopic depth estimates varied directly with magnitude and direction of disparity; however, depth magnitude reports were truncated when the disparity was carried by discontinuously defined patterns.
\end{abstract}

Julesz (1971) and others (Harris \& Gregory, 1973; Lawson \& Gulick, 1967) have shown that contour perception can arise with or without corresponding gradients of brightness, hue, or saturation in the optical display. The former are examples of objective contours (with abrupt gradients), while the latter are called subjective contours (without abrupt gradients; Lawson \& Gulick, 1967). Objective contours can be divided readily into various levels of clarity simply by varying the abruptness of the luminance or chromatic gradients; however, such manipulations thus far appear not to affect the clarity of subjective contour perception (Shipley, 1965).

Although Schumann (1904) was the first to study systematically subjective contours, a more robust subjective contour display was introduced by Kanisza (1955). Figure 1 presents a variation of the original Kanisza pattern. Most observers report that the white square appears in front of the black elements, that it appears brighter than the white surround, and that the square is bounded on all four sides by clearly defined edges even though only the corners are defined by abrupt brightness gradients. Subjective contours are also reported when half-images of such squares are decentrated and crossed disparity is used. Clearly, subjective contours can arise with or without stereoscopic depth separation.

Coren (1972) has suggested that the monocular interposition cue as well as other depth cues (e.g., texture gradients) give rise to subjective contours when the optical display is confined to a two-dimensiona! surface. Furthermore, others have demonstrated that increasing the perceived stereoscopic depth separation between the form bounded by subjective contours and the remaining elements of the display enhances the clarity of these contours providing the disparity is crossed or positive

This research was supported by NSF Grant GB-43278 to R.B.L. The authors thank $D$. Whitmore for assistance with data analyses. Requests for reprints should be sent to: Robert B. Lawson, Psychology Department. John Dewey Hall. University of Vermont, Burlington, Vermont 05401 .

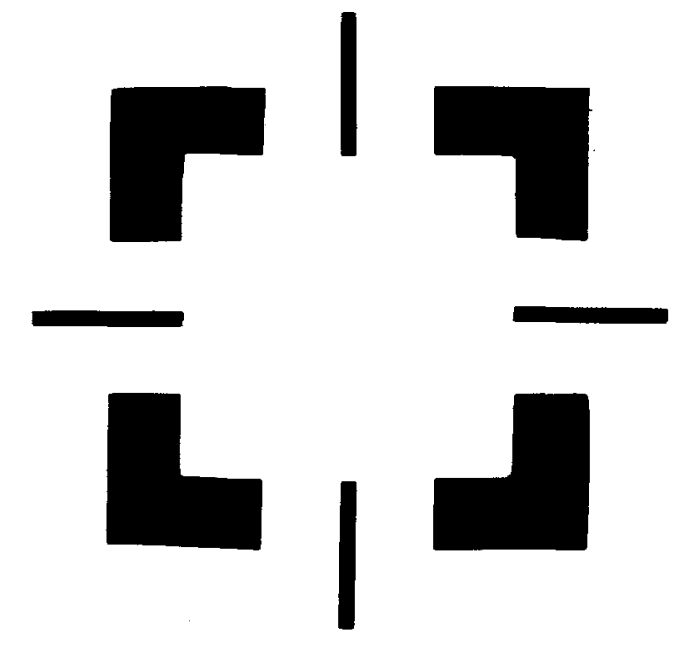

Figure 1. Modified Kanisza pattern defined by solid black corners.

(Bloomfield, 1973; Gregory \& Harris, 1974; Harris \& Gregory, 1973; Lawson, Cowan, Gibbs, \& Whitmore, 1974). However, when the disparity carried by Kanisza displays is uncrossed or negative, the clarity of the subjective contours is degraded or these contours are eliminated from the perceptual experience (Gregory \& Harris, 1974; Lawson et al., 1974). These findings indicate that the clarity of subjective contours can be enhanced when at least two compatible depth cues (interposition and crossed disparity) are present in the optical display, while the presence of incompatible depth signals (interposition and uncrossed disparity) attenuates the clarity of these contours.

Although portions of the original Kanisza pattern are detined by continuous objective contours, subjective contours have also been reported by Lawson and Gulick (1967) for matrix element patterns in which no portion of the disparate form is bounded by abruptly defined continuous contours. Here, the subjective contours depend on the presence of disparity, because they arise only after stereoscopic 


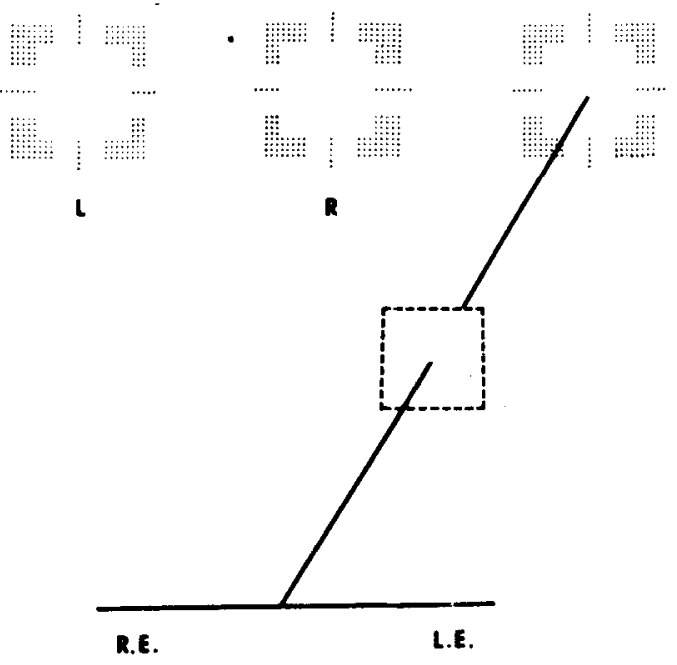

Figure 2. Modified Kanisza pattern defined by dot pattern corners and the stereoscopic organization that results with crossed disparities.

combination of disparate matrix half-views. Although subjective contours can arise monocularly and stereoscopically, some examples of stereoscopic subjective contours can arise in the presence and absence of disparity, providing the monocular disparate form is bounded by continuous objective contours. while other examples arise only when disparity is present if the monocular configuration is defined by a matrix of dots or other discontinuous elements. The purpose of this experiment was to determine the effects of the magnitude and direction of disparity carried by continuously defined (black corners) and discontinuously defined (dot corners) Kanisza-type patterns upon stereoscopic depth and subjective contour perception.

\section{Subjects}

\section{METHOD}

Three males and four females (mean age 25.71 years) served as subjects. Each had normal near visual acuity (20/17-20/25), normal lateral (3-6), and vertical (6-9) phoria expressed as prism diopter equivalents, and normal stereopsis ( $90 \%$ Fry-Shepard) scores as measured with a Bausch and Lomb Orthorater (Model 71-21-31).

\section{Apparatus}

Two types of experimental stereograms were employed. In one type. the central white square was bounded by spatially contiguous homogeneous black corners (Figure 1), while the other contained dots defining the corners of the square (Figure 2). For both types of stereograms, the angular size of the outer defining square was $3.15^{\circ}$ on a side while the inner white square was $1.98^{\circ}$ on a side. The disparity carried by the inner square varied from $-0.42^{\circ}$ through zero to $+0.42^{\circ}$ in steps of $0.21^{\circ}$ of visual angle. All stereograms were viewed in a prism stereoscope at a distance of $84 \mathrm{~cm}$.

\section{Procedure}

The subjects were instructed to make stereoscopic distance estimates of the white square by considering the distance between their eyes and the lower black squares of the configuration as equal to 100 units. Depth estimates of less than 100 indicated that the white square appeared in front of the black elements, while estimates greater than 100 ind icated that the white square appeared behind the black elements of the configuration.

To estimate the clarity of the subjective contours, the subjects varied the clarity of a projected white square $\left(15.8^{\circ}\right.$ on a side) seen against a gray ground presented at a viewing distance of $22.8 \mathrm{~cm}$. Each subject varied the focal length of the projector by depressing a switch that moved the projector lens (Kodak Ektagraphic Model B, f $3.5,5^{\prime \prime}$ lens) back and forth until the clarity of the projected edges matched the clarity of the subjective contours appearing in the stereoscopic field. Prior to the start of the experiment, the lens setting that produced the clearest contour defining the projected image for all subjects was identified as zero on a circular scale mounted on the lens control knob of the projector. The luminance values of the projected white square and the gray ground at the 0 scalar setting were $401.2 \mathrm{~cd} / \mathrm{m}^{2}$ and $242 \mathrm{~cd} / \mathrm{m}^{2}$, while at the scalar value of 10 these were $347.1 \mathrm{~cd} / \mathrm{m}^{2}$ and $242 \mathrm{~cd} / \mathrm{m}^{2}$, respectively. For these two scalar settings, the contrast ratios between the square and gray ground were 1.64:1 and 1.43:1, respectively, as measured with a Macbeth illuminometer. The subjects were instructed to look back and forth from the projected square to the stereoscopically displayed image in order to make their contour clarity estimates. Although the viewing time was unrestricted, all subjects made their judgments within a 2 -min inspection interval.

The 10 experimental stereograms were presented as two randomized blocks. with each subject viewing twice each experimental stereogram.

\section{RESULTS}

The present results indicate clearly that the direction of disparity and the type of pattern carrying the disparity information influenced directly the perceived clarity of subjective contours appearing in stereoscopic space. Depth estimates were also affected significantly by disparity accompanied by a depth truncation effect for the dot patterns.

Figure 3a presents the mean depth magnitude estimates based upon all seven subjects for the solid and dotted Kanisza cornered patterns at all disparity levels. For both pattern types, depth was linearly related to disparity. For the dot patterns, however. depth estimates were truncated toward the 100-unit module regardless of the direction of disparity. An analysis of variance of the mean depth estimates based on all seven subjects indicated that the main effect of disparity, $F(4,24)=42.068, p<.001$, and the Disparity by Pattern Type interaction, $F(4,24)=$ 5.734, $\mathrm{p}<.01$, were significant.

Figure $3 \mathrm{~b}$ presents the mean contour clarity estimates based upon all seven subjects for the solid and dotted patterns at all five disparity levels. Note that, with crossed disparities, the subjects always reported an enhancement of the clarity of the subjective contours compared to the zero disparity condition. With uncrossed disparities, there was a marked reduction in the clarity of the subjective contours. The dotted patterns were accompanied by a marked reduction in the clarity of the subjective contours as compared to the black corner pattern at all disparity levels, indicating that contour clarity varies as a function of the type of configuration carrying the disparity information. Also, with uncrossed disparities, the subjects reported that subjective contours were present along the inner 
corners of the interrupted dot display while the enclosed central region appeared unbounded but recessed from the dotted corners.

An analysis of variance of the contour clarity estimales indicated that only the main effects of disparity, $F(4,24)=12.542, p<.001$, and pattern type, $F(1,6)=5.848, p<.05$, were signiticant.

None of the subjects reported any difficulty in combining and maintaining any of the half-images in binocular register.

\section{DISCUSSION}

The present findings indicate that the clarity of subjective contour is influenced markedly not only by disparity, but also by the type of configuration in the monocular displays.

The present tindings that crossed disparities carried by modified Kanisza displays gives rise to depth and enhanced subjective contours agrees with the results of other studies that were confined only to Kanisza patterns defined by solid rather than dotted elements (Bloomtield, 1973; Gregory \& Harris, 1974; Harris \& Gregory, 1973; Lawson et al., 1974). It appears that the clarity of subjective contours can be varied either by manipulating separately monocular (type of configuration) and binocular (disparity) variables or manipulating jointly both sets of variables. Subjective contours can occur under a variety of viewing conditions.

The fact that the subjective edges arising in the inner corners of the dot patterns remained coplanar with the dots rather than bounding the more remote central disparate white form that carried a negative disparity agrees with findings reported by Lawson, Gulick, and Park (1972). They found that subjective contours produced by disparate dot-matrix patterns were localized with the disparate portion of the display when the disparity was crossed but not uncrossed. These two sets of findings indicate that the stereoscopic organization of a display and the consequent position of subjective contours in stereoscopic space is not determined solely by disparity.

The present result, that stereoscopic depth varied directly with the magnitude and direction of disparity, is in agreement with Lawson, Gulick, and Park (1972), who found a linear relationship between disparity magnitude and stereoscopic depth. Similarly. the truncated depth reports arising from the negatively disparate interrupted element patterns is consistent with findings by Whitmore (Note 1), who also found a depth truncation effect with negatively disparate random-element Jules\% patterns but not with line-drawn or solid-surface patterns.

The type of monocular configuration influences markedly not only the clarity of subjective contours. but also depth magnitude reports, particularly with negatively disparate displays. Clearly, the magnitude
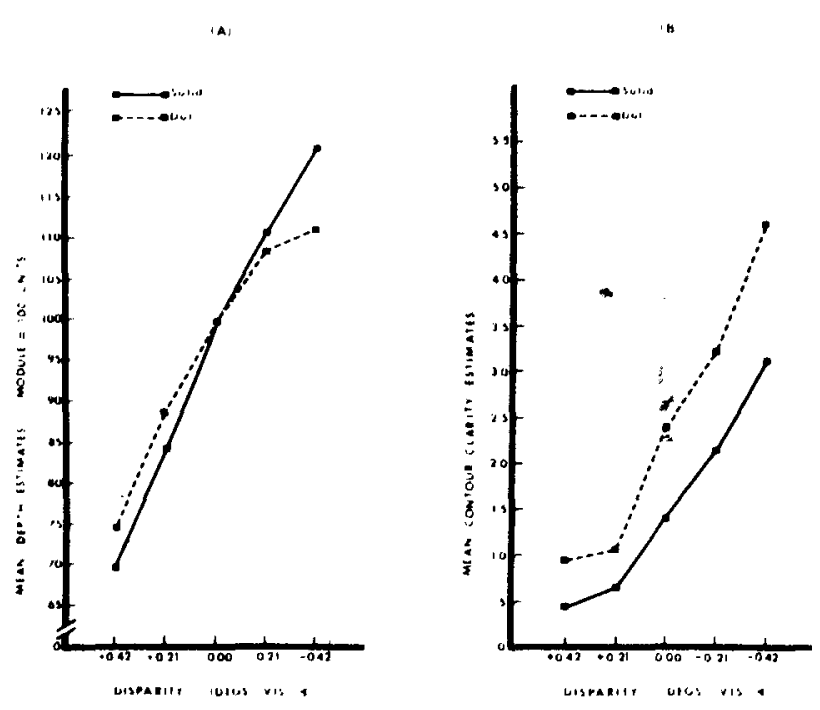

Figure 3. (a) Mean depth estimates for all seven subjects for the solid and dotted Kanisza patterns at all five disparity levels; (b) mean contour clarity estimates for all seven subjects for the solid and dotted pattems at all five disparity levels.

of stereoscopic depth is not determined solely by the magnitude of disparity carried by a display.

\section{REFERENCE NOTE}

1. Whitmore, C. L. The effects of disparity, contour, and temporal factors upon human stereoscopic depth perception. Paper presented at the annual meeting of the Eastern Psychological Assuciation, New York, April 1975.

\section{REFERENCES}

Bloomfield, S. Implicit features and stereoscopy. Nature-New Biology, 1973, 245, 256.

Coren, S. Subjective contours and apparent depth. Psychological Revic's', 1972, 79, 359-367.

GREGory, R. L., \& HarRIS, J. P. Illusory contours and stereo depth. Perception \& Psychophysics, 1974, 15, 411-416.

Harris, J. P., \& Gregory, R. L. Fusion and rivalry of illusory contours. Perception, 1973, 2, 235-247.

Julesz, B. Foundations of cyclopean perception. Chicago: University of Chicago Press, 1971.

KaniszA, G. Marzini quasi-percettivi in campi con stimolazion omogenea. Rivista di psicologia, 1955, 49, 7-30.

Lawson, R. B., Cowan, E., GibBs, T. D., \& Whitmore, C. G. Stereoscopic enhancement and erasure of subjective contours. Journal of Experimental Psychology, 1974, 103, 1142-1146.

Lawson, R. B., \& Gulıck, W. L. Stereopsis and anomalous contour. Vision Research, 1967, 7, 271-297.

Lawson, R. B., Gulick, W. L., \& Park, M. Stereoscopic size-distance relationships from line-drawn and dot-matrix stereograms. Journal of Experimental Psychology, 1972, 92. 69.74.

Schumann, F. Einige Beobachtungen über die Zusammenfassung von Giesichtseindrucken zu Einheiten. Psychologische Studien, $19(04,1,1-32$.

Shipley, T. Visual contours in homogeneous space. Science. $1965,150,348-350$.

(Received for publication July 7, 1975; revision received November 20,1975 .) 